\title{
OPTIMIZATION OF COMPOSITION AND FORMATION OF TITANIA SOL-GEL COATINGS ON TITANIUM SUBSTRATE USING DIP-COATING TECHNIQUE
}

\author{
"KRISTÝNA ŠVAGROVÁ, DIANA HORKAVCOVÁ, ALEŠ HELEBRANT \\ Department of Glass and Ceramics, Faculty of Chemical Technology, University of Chemistry and Technology Prague, \\ Technická 5, 16628 Prague 6, Czech Republic \\ "E-mail: svagrovk@vscht.cz
}

Submitted February 7, 2019; accepted April 8, 2019

\begin{abstract}
Keywords: Sol-gel, Dip-coating, Titanium substrate, Bioactive coating, Bioactivity
The objective of this work was to use a sol-gel method to prepare bioactive coatings containing calcium and phosphate ions under various coating conditions on a non-porous titanium substrate. Titania sol based on tetra-n-butyl-orthotitanate was prepared by direct dissolution of reagents and from stock ethanol solutions. The titanium substrate was grinded and coatings were prepared on the surface using a dip-coating technique under different coating conditions which are critical for preparation of sol-gel coatings. The conditions, which included the coating speed, chosen reagents and other experimental conditions, were selected based on previous experiments. The coating process was followed by drying for various periods of time and firing of the coated substrates. Bioactivity of the fired coatings was tested with a static in vitro test in simulated body fluid. After the firing and after the in vitro test the coatings were characterized with an optical microscope and with a scanning electron microscope. After the firing all types of coatings were made up of white circle areas of diverse morphology. After the in vitro test all types of the coatings contained a new Ca-P nuclei and white Ca-P phases of diverse morphology and size. The most continual precipitated Ca-P phases were detected on a sample prepared at the dipping and withdrawal speed of $20 \mathrm{~cm} \cdot \mathrm{min}^{-1}$ with the dwell time of $30 \mathrm{~s}$.
\end{abstract}

\section{INTRODUCTION}

Titanium and its alloys have been widely used in biomedicine applications. They meet strict biological, mechanical, as well as chemical requirements. Their characteristic features include good ductility, malleability, mechanical and chemical resistance, biocompatibility and resistance to corrosion thanks to a thin native layer of titanium dioxide $[1,2]$. With regard to the above described desirable properties they are most frequently used as a replacement of hard tissues, i.e. as bone, joint and dental implants [3]. The sol-gel method has been given more attention in recent years thanks to a wide range of its possible applications. It has a great potential in preparation of thin coatings, it allows variable composition of initial sols, morphology and control of functions of the resulting coating. The method permits to enrich existing properties of the inert titanium substrate with new features $[4,5]$.

Selection of a suitable method to apply the sol on the substrate depends on many critical parameters, particularly on its composition, viscosity, ageing and conditions of sol preparation, type of the substrate, its porosity, shape, required thickness of the coating, requirements for the technological procedure and, last but not least, its price [6]. The three most frequently used methods to apply coatings used for research and industrial purposes are spin-coating [7], spray-coating [8] and dip-coating [9]. Each of the methods has its advantages and disadvantages. The dip-coating technique is based on dipping of a substrate into a sol at a given temperature, speed and humidity or stirring. It is an inexpensive and fast technique for preparation of coatings on substrates of various shapes and sizes $[10,11]$. When using the right reagents and appropriate coating conditions the resulting coats are homogenous, with a specific thickness, bioactive ability [12], excellent adhesion [13] and other properties. A key role is played by the coating conditions which may influence thickness of the coating, its homogeneity and functional properties. Coating thickness could be controlled by the withdrawal speed: high withdrawal speed means a thicker coat and low withdrawal speed means a thinner coating. Another option is multiple dipping which produces a thicker multilayer coating [4].

Bioactivity in vitro can be estimated based on the ability of the material to create apatite on the substrate surface and most frequently it is tested in simulated body fluid in accordance with the standard ISO 23317:2014 [14]. Hydroxyapatite is a bioactive ceramic material that has been widely used as a replacement of hard tissues thanks to its similarity to mineral composition of natural bones, although it is too brittle. Therefore, a new trend has appeared in preparation of bioactive coatings 
that support osteoconduction of metallic implants [15]. In order to achieve the desired bioactive properties the resulting sol was prepared from stock ethanol solutions of calcium nitrate tetrahydrate and triethylphosphate that were subsequently added in the basic titania sol so that the resulting ratio $\mathrm{Ca} / \mathrm{P}$ is 1.67 . This is the ratio of calcium and phosphorus detected in the bone apatite and thus it has been used to simulate the human body environment as close as possible [16].

The objective of the work was to optimize and to find the most appropriate conditions for development of coatings created from titania sol and containing calcium and phosphate ions by the dip-coating technique. At the same, we have tested potential bioactivity of the prepared coatings with an in vitro test in simulated body fluid and subsequently we selected the best coatings for further testing.

\section{EXPERIMENTAL}

\section{Substrate}

Samples used for coating were made of titanium sheet (Grade 2), sized $30 \times 10 \times 1 \mathrm{~mm}$, gradually grinded with abrasive papers with SiC grit size P400, P600, P800. The grinding was necessary to remove impurities from the surface, to make the surface uniform and to achieve the same roughness on all samples. Another necessary step was to clean the samples with ultrasonic bath, by immersing them for 10 minutes in acetone and for 10 minutes in ethanol. The prepared samples were then dried at room temperature.

\section{Preparation of the sols}

The basic titania sol was prepared by mixing of Triton $\mathrm{X}-100,1 \mathrm{~mol} \cdot \mathrm{l}^{-1}$ nitric acid, acetylacetonate and tetra-n-butyl-orthotitanate. In the first group the basic titania sol was used to directly dissolve triethyl phosphate

Table 1. Conditions of final coatings formation.

\begin{tabular}{lccc}
\hline Coating & $\begin{array}{c}\mathrm{v}_{1} \\
\left(\mathrm{~cm} \cdot \mathrm{min}^{-1}\right)\end{array}$ & $\begin{array}{c}\text { Dwell time } \\
(\mathrm{s})\end{array}$ & $\begin{array}{c}\mathrm{v}_{2} \\
\left(\mathrm{~cm} \cdot \mathrm{min}^{-1}\right)\end{array}$ \\
\hline TCaP 1 & 20 & 1 & 30 \\
TCaP 2 & 20 & 10 & 30 \\
TCaP 3 & 20 & 30 & 30 \\
TCaP 4 & 20 & 30 & 10 \\
TCaP 5 & 20 & 30 & 20 \\
\hline
\end{tabular}

and calcium nitrate tetrahydrate. For the second group we first prepared ethanol solutions of trietylphosphate and calcium nitrate tetrahydrate with the concentration of $2 \mathrm{~mol} \cdot \mathrm{l}^{-1}$. The titania sol and the ethanol solutions were homogenized for 24 hours at room temperature. Subsequently, the ethanol solutions were added to the basic titanium sol to achieve the resulting ratio of $\mathrm{Ca} / \mathrm{P}=1.67$ and the sol $(\mathrm{TCaP})$ was then homogenized for 24 hours.

\section{Dip-coating conditions}

The coating was applied by using dip-coating technique with stirring (in order to achieve homogeneity in the entire sol volume) at room temperature. The dipping speed was the same throughout the whole test duration $\left(\mathrm{v}_{1}=20 \mathrm{~cm} \cdot \mathrm{min}^{-1}\right)$, the dwell time ranged from 1 to $30 \mathrm{~s}$ and the withdrawal speed was $\mathrm{v}_{2}=10-30 \mathrm{~cm} \cdot \mathrm{min}^{-1}$. Table 1 shows selected conditions for formation of coatings in the second group $\mathrm{TCaP} 1, \mathrm{TCaP} 2, \mathrm{TCaP} 3$, TCaP 4, TCaP 5. The drying times of the coatings from the first group ranged from 15 minutes to 2 hours at room temperature. Coatings from the second group was performed with the drying time of 15 minutes. All coated substrates were fired up to $400{ }^{\circ} \mathrm{C}$ for 2 hours with the temperature increase of $2{ }^{\circ} \mathrm{C} \cdot \mathrm{min}^{-1}$. The samples were fired in the air atmosphere and spontaneously cooled down in the oven until the following day.

\section{Conditions of in vitro test}

Bioactivity, i.e. the ability to form apatite on the finally selected coated substrates after firing, was tested using an in vitro test in simulated body fluid (SBF) in accordance with the standard ISO 23317:2014. The si-mulated body fluid was prepared by gradual dissolution of reagents at the constant temperature of $36.5 \pm$ $\pm 1.5{ }^{\circ} \mathrm{C}$ with continual stirring. Table 2 shows concentration of ions in SBF in comparison with concentration of ions in human blood plasma (BP). Two samples with the same type of coating were immersed into plastic bottle with SBF. The resulting ratio of the surface of the tested sample and the SBF volume was 0.1 as required by the standard $(\mathrm{S} / \mathrm{V})$. The samples were left in a thermostat at $36.5^{\circ} \mathrm{C}$ for 30 days. Then they were removed from simulated body fluid, washed three times in demineralized water and left to dry in the air at room temperature. The samples were subsequently characterized with an optical microscope and with a scanning electron microscope.

Table 2. Concentration of ions in simulated body fluid (SBF) and in human blood plasma (BP) [12].

\begin{tabular}{lccccccrr}
\hline Solution & \multicolumn{7}{c}{ Concentration of ions $\left(\mathrm{mmol} \cdot \mathrm{dm}^{-3}\right)$} \\
\cline { 2 - 8 } & $\mathrm{Na}^{+}$ & $\mathrm{K}^{+}$ & $\mathrm{Mg}^{2+}$ & $\mathrm{Ca}^{2+}$ & $\mathrm{Cl}^{-}$ & $\mathrm{HCO}_{3}^{-}$ & $\mathrm{HPO}_{4}^{2-}$ & $\mathrm{SO}_{4}^{2-}$ \\
\hline BP & 142.0 & 5.0 & 1.5 & 2.5 & 103.0 & 27.0 & 1.0 & 0.5 \\
SBF & 142.0 & 5.0 & 1.5 & 2.5 & 147.8 & 4.2 & 1.0 & 0.5 \\
\hline
\end{tabular}


Characterization of substrate and coatings

\section{Optical microscopy and scanning electron microscopy with EDS analysis}

The surface of the substrate after mechanical treatment and all types of coatings after firing were characterized with optical microscope BX-50 (Olympus). The surface of the substrate after mechanical treatment, all types of coatings after firing and, subsequently, also after the static in vitro test were characterized with the scanning electron microscope (SEM) Hitachi S-4700 using the accelerating voltage $15 \mathrm{kV}$ with the EDS analyzer Thompson Scientific Ultradry Silicon Drift Detector. The samples were covered with a layer of $\mathrm{Au} / \mathrm{Pd}$.

\section{RESULTS AND DISCUSSION}

Mechanical treatment of the substrate was performed to clean the surface and to make it rough so that the coating can better adhere on it. Figure 1 shows a homogeneous surface of the titanium substrate without impurities, with a clearly visible relief after grinding.

The treated substrate was covered with a titania sol enriched with $\mathrm{Ca}$ and $\mathrm{P}$ (in order to acquire bioactive properties). The first group was enriched with $\mathrm{Ca}$ and $\mathrm{P}$ by direct dissolving of reagents and the second group was prepared from stock ethanol solutions under different coating conditions. The objective of the experimental work was to find the most suitable coating conditions to produce homogeneous and bioactive coatings. Coatings in the first group, after drying and firing, were inhomogeneous, they were cracking and peeling off. Those coatings were not used for further testing.

Figures 2a-e provide SEM images of coatings from the second group after the firing. The coatings are not completely homogeneous and their thickness is not the same on the entire surface. All coatings were made up of white circle areas evenly distributed all over the surface.

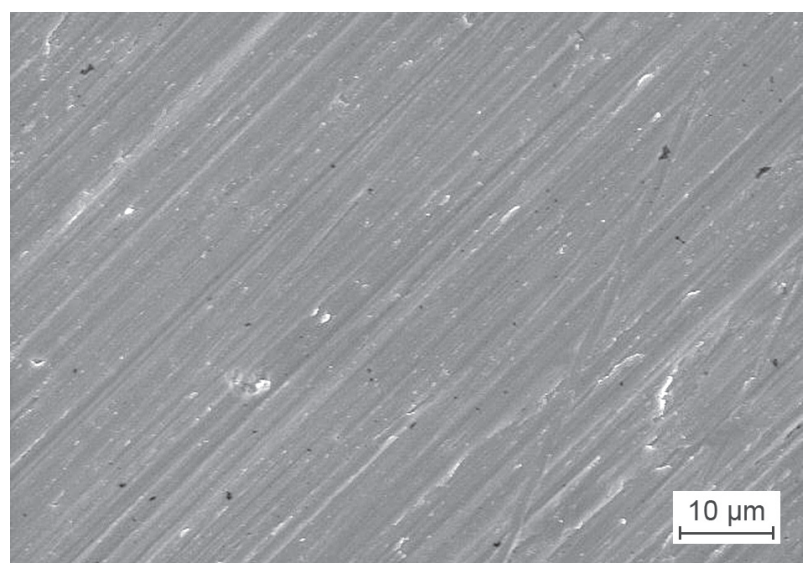

Figure 1. Surface of the titanium substrate after mechanical treatment.
The particles of calcium confirmed by the EDS analysis were detected inside this circles. There is a visible dark area surrounding the white calcium particles (an integral coating) containing phosphate ions (according to the EDS analysis).

In the coating TCaP 2 (Figure $2 \mathrm{~b}$ ) the white circle areas containing calcium are less separated than in the coating TCaP 1 (Figure 2a). The interfaces between these individual white circles are in this case more

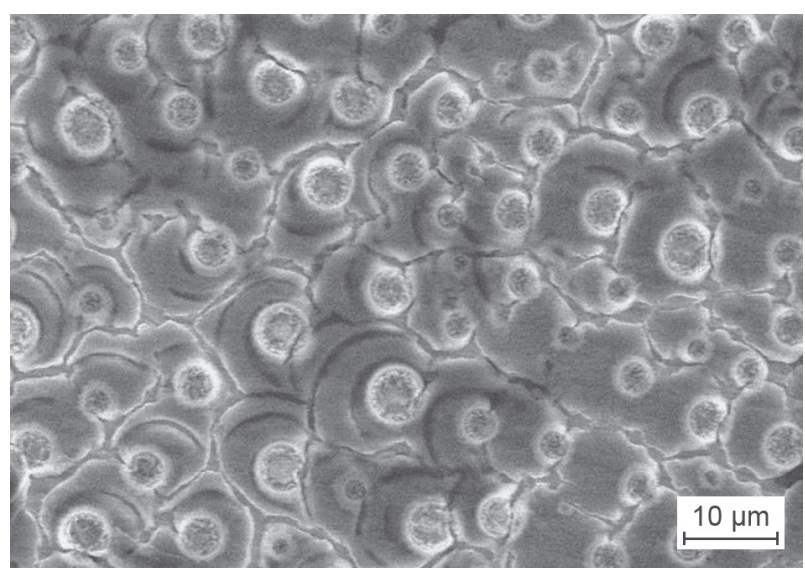

a) $\mathrm{TCaP} 1$

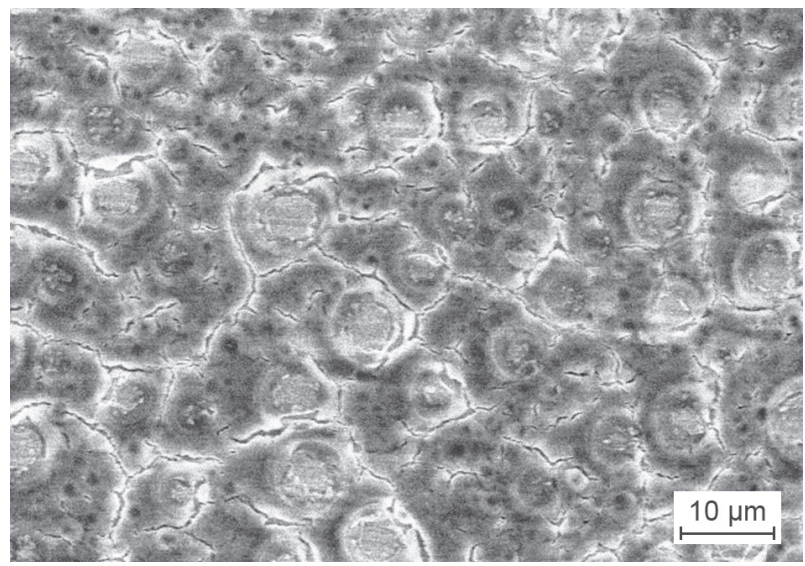

b) TCaP 2

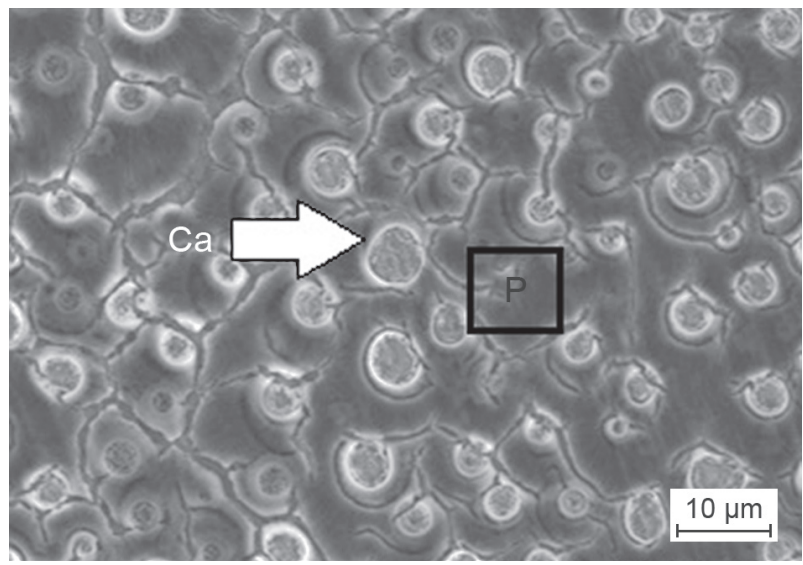

c) $\mathrm{TCaP} 3$

Figure 2. Surface of the second group of coatings on titanium substrate after the firing (SEM). (Continue on next page) 


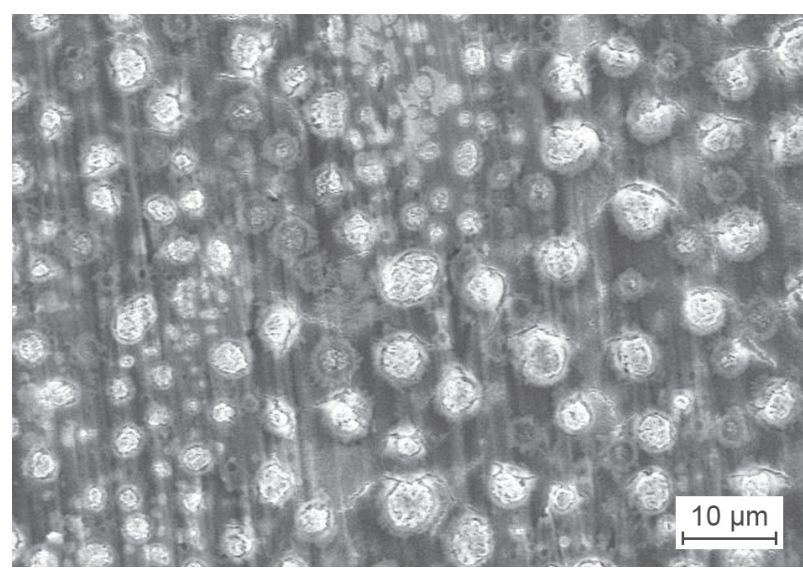

d) $\mathrm{TCaP} 4$

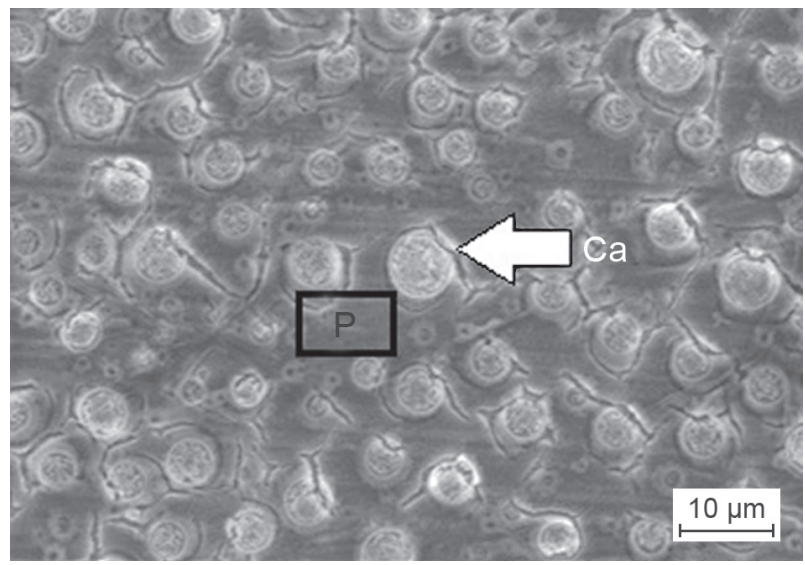

e) TCaP 5

Figure 2. Surface of the second group of coatings on titanium substrate after the firing (SEM).

distinct. The white bordered circle areas in the TCaP 3 coating image (Figure 2c), with a dark relief inside, have a dark map around the surface and they are not more separated from circles in their proximity. White particles of calcium visible in the image of the TCaP 4 coating (Figure 2d) have a clear relief and they are not more isolated from other circles in their proximity. The last type TCaP 5 (Figure 2e) is similar to the TCaP 3 coating, however, with a less distinct border and less cracking.

Figures 3a-e show SEM images of coatings after the static in vitro test of bioactivity. It is obvious that typical globules of apatite nano-plates did not precipitate on surfaces of coatings from the second group. However, in all types of coatings a zone of a new white $\mathrm{Ca}-\mathrm{P}$ phases of diverse morphology were detected, which have been confirmed by the EDS analysis.

The TCaP 1 coating(Figure 3a) contained small Ca-P nuclei and $\mathrm{Ca}-\mathrm{P}$ precipitates. The new $\mathrm{Ca}-\mathrm{P}$ nuclei precipitate from white circle areas in the coating. These $\mathrm{Ca}-\mathrm{P}$ nuclei created white $\mathrm{Ca}-\mathrm{P}$ precipitates sized up to $10 \mu \mathrm{m}$. The EDS analysis has confirmed an increased representation of $\mathrm{Ca}$ and $\mathrm{P}$. The image of the TCaP 2 coating (Figure $3 \mathrm{~b}$ ) shows that a new $\mathrm{Ca}-\mathrm{P}$ nuclei of different sizes has evenly developed on the entire surface and they spread further on the surface (most likely one of apatite precursors). It develops in the places of white circle areas and inside them, and also on the integral coatings and in many locations it covers cracks in the coating. The image of the TCaP 3 coating (Figure 3c) shows cracks surrounding the individual white areas. The inside of the circle areas is fairly disintegrated. New small $\mathrm{Ca}-\mathrm{P}$ nuclei and $\mathrm{Ca}-\mathrm{P}$

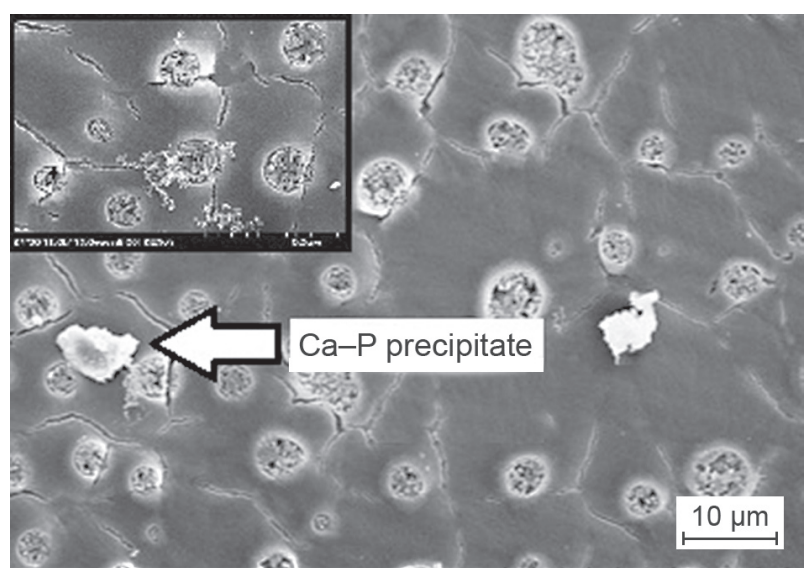

a) $\mathrm{TCaP} 1$

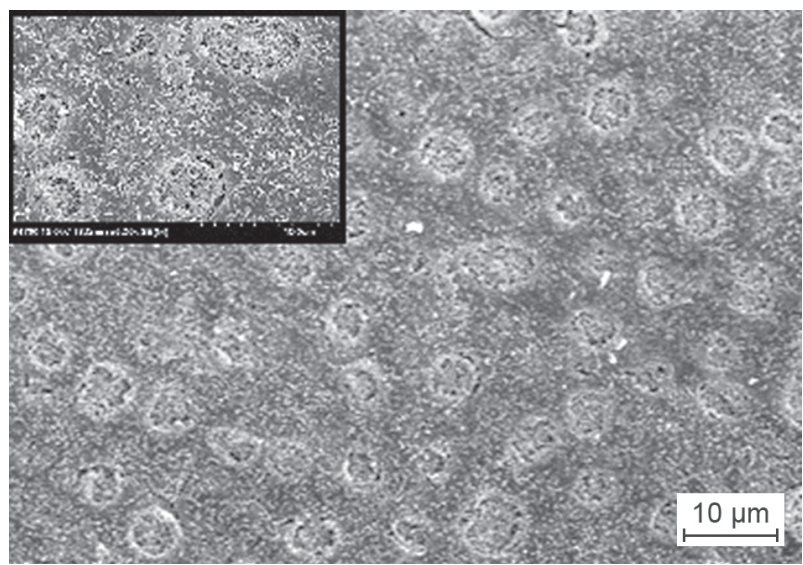

b) $\mathrm{TCaP} 2$

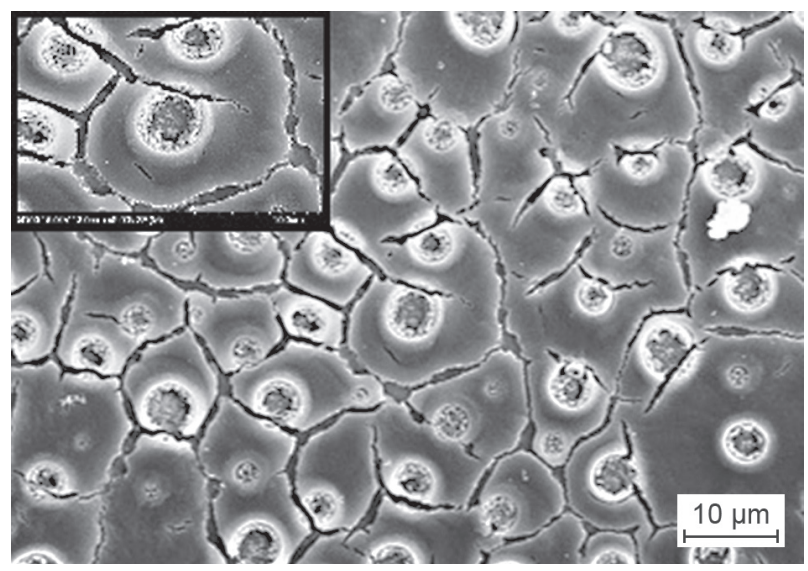

c) $\mathrm{TCaP} 3$

Figure 3. Surface of the second group of coatings after in vitro test (SEM). (Continue on next page) 


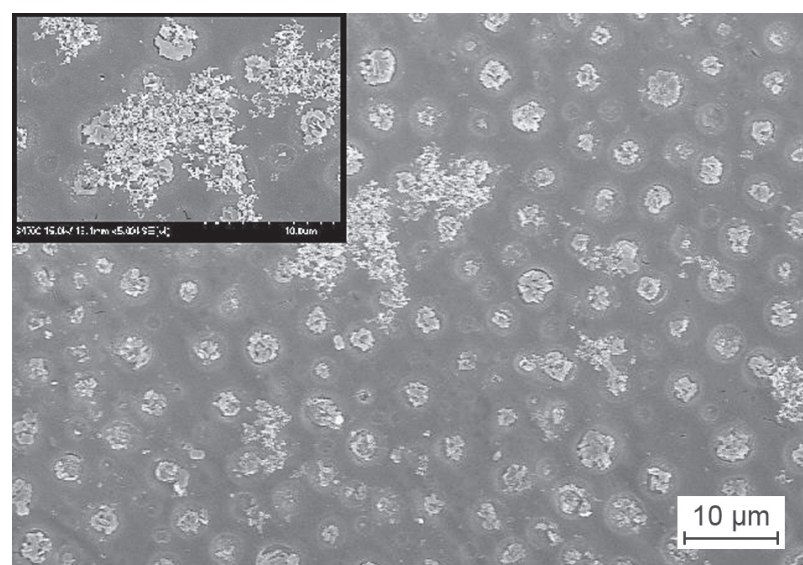

d) $\mathrm{TCaP} 4$

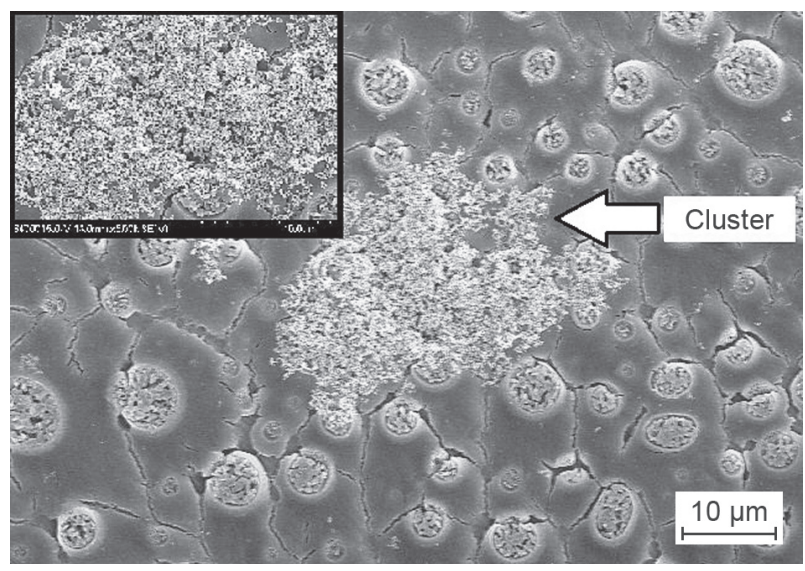

e) $\mathrm{TCaP} 5$

Figure 3. Surface of the second group of coatings after in vitro test (SEM).

precipitates are randomly situated on the coating. The quantity of the newly pre-cipitated phases was the lowest in comparison with the other coatings (as confirmed by the EDS analysis). The newly created $\mathrm{Ca}-\mathrm{P}$ nuclei and $\mathrm{Ca}-\mathrm{P}$ clusters could be seen in the TCaP 4 coating (Figure 3d). They were detected evenly all over the surface while they primarily developed in the white circle areas with $\mathrm{Ca}$ particles and completely covered them. Further, the circle areas in the coating surface were completely covered with the new precipitated $\mathrm{Ca}-\mathrm{P}$ clusters. The TCaP 4 coating practically does not contain any cracks. The EDS analysis clearly indicates that those $\mathrm{Ca}-\mathrm{P}$ clusters contain calcium and phosphorus. Figure 3e (TCaP 5) shows a newly developed phase, again probably a pre-phase of apatite according to the EDS analysis that confirmed existence of $\mathrm{Ca}$ and $\mathrm{P}$ elements. The newly precipitated phase is also shaped to $\mathrm{Ca}-\mathrm{P}$ clusters (sized up to several tens of $\mu \mathrm{m})$. These $\mathrm{Ca}-\mathrm{P}$ clusters precipitate inside white circles areas and cover a large area of the coating and small isolated cracks, as well as circle areas.

\section{CONCLUSIONS}

Different conditions were used to prepare titania sols and subsequently titania coatings. Coatings from the first group, prepared by direct dissolution of reagents, were excluded from further testing due to their unsatisfactory final properties. Selected titania so-gel coatings, containing calcium and phosphate ions and prepared by dip-coating technique under different coating conditions, were after their firing made up of white circle areas. The individual coating types visually differed from one another. Based on the SEM images the best coating due to homogeneity was TCaP 5.

The in vitro test did not confirm formation of precipitated crystalline apatite on the coating surface. However, places with a new created $\mathrm{Ca}-\mathrm{P}$ phases with different morphology were detected on all types of coatings in this experiment. The highest quantity of precipitated $\mathrm{Ca}-\mathrm{P}$ phases was found on the sample TCaP 5 and therefore the coating has been evaluated as the most suitable for further experimental measurements.

\section{Acknowledgement}

This work was supported by the Technology Agency for the Czech Republic within the project TE01020390 Center for development of modern metallic biomaterials for medicinal implants.

\section{REFERENCES}

1. Vojtěch D. (2006). Kovové materiály. $1^{\text {st }}$ ed.Praha, Vydavatelství VŠCHT.

2. Vojtěch D. (2010). Materiály a jejich mezní stavy. $1^{\text {st }}$ ed. Praha, Vydavatelství VŠCHT.

3. Qu J., Lu X., Li D., Ding Y., Leng Y., et al. (2011): Silver/ hydroxyapatite composite coatings on porous titanium surfaces by sol-gel method. Journal of Biomedical Materials Research Part B: Applied Biomaterials, 97(1), 40-48. doi: 10.1002/jbm.b.31784

4. Švagrová K. (2018). Př́íprava a charakterizace titaničitých sol-gel povlaků s obsahem Ag, Ca a P na titanu. Diplomová práce. Vysoká škola chemicko-technologická v Praze.

5. Catauro M., Bollino F., Giovanardi R., Veronesi P. (2017): Modification of Ti6Al4V implant surfaces by biocompatible $\mathrm{TiO}_{2} / \mathrm{PCL}$ hybrid layers prepared via sol-gel dip coating: Structural characterization, mechanical and corrosion behavior. Materials Science and Engineering: C, 74, 501-507. doi: 10.1016/j.msec.2016.12.046

6. Gupta R., Kumar A. (2008): Bioactive materials for biomedical applications using sol-gel technology. Biomedical Materials, 3(3), 034005. doi: 10.1088/1748-6041/3/3/ 034005

7. Xu W., Hu W., Li M., Wen C. (2006): Sol-gel Hydroxyapatite/ Titania Biocoating on Titanium Substrate. Materials Letters, 60, 1575-1578. doi: 10.1016/j.matlet.2005.11.072

8. Lopez L., Daoud W., Dutta D. (2010): Preparation of large scale photocatalytic $\mathrm{TiO}_{2}$ films by the sol-gel process. Surface and Coatings Technology, 205, 251-257. 
doi:10.1016/j.surfcoat.2010.06.028

9. Brinker Ch., Hurd A. (1994): Fundamentals of Sol-Gel Dip-Coating. Journal de Physique III, 4, 1231-1242. doi:10.1051/jp3:1994198

10. Horkavcova D., Zmeskal Z., Sanda L., Zlámalová Cúlová Z., Jablonska E., Helebrant A. (2015): Preparation of titania sol-gel coatings containing silver in various forms and measuring of their bactericidal effects against E. coli. Ceramics- Silikáty, 59, 238-243.

11. Sakka S. (2013). Sol-Gel Process and Applications, Chapter 11.1.2. in: Handbook of Advanced Ceramics. $2^{\text {nd }}$ ed. Academic Press. pp. 883-910. doi:10.1016/B978-0-12385469-8.00048-4

12. Kokubo T., Takadama H. (2006). How Useful is SBF in Predicting in vivo Bone Bioactivity? Biomaterials, 27, 2907-15. doi:10.1016/j.biomaterials.2006.01.017

13. Chalker P., Bull S., Rickerby D.S. (1991): A Review of the
Methods for the Evaluation of Coating-Substrate Adhesion. Materials Science and Engineering A-Structural Materials Properties Microstructure and Processing, 140, 583-592. doi:10.1016/0921-5093(91)90482-3

14. ISO 23317:2014. Implants for surgery - In vitro evaluation for apatite-forming ability of implant materials. Berlin: DIN Deutsches Institut für Normung e.V., 2014. p.13

15. Kim H.-W., Koh Y.-H., Li L., Lee S., Kim H.-J. (2004). Hydroxyapatite Coating on Titanium Substrate with Titania Buffer Layer Processed by Sol-Gel Method. Biomaterials, 25, 2533-2538. 10. doi:1016/j.biomaterials.2003.09.041

16. Sidane D., Rammal H., Beljebbar A., Gangloff S., Chicot D., Velard F., Khireddine H., Montagne A., Kerdjoudj H. (2016): Biocompatibility of sol-gel hydroxyapatite-titania composite and bilayer coatings. Materials Science and Engineering C, 72, 650-658. doi:10.1016/j.msec.2016.11.129 